Treatment of radiotherapy and related morbidity

\title{
Randomised phase II trial of hyperbaric oxygen therapy in patients with chronic arm lymphoedema after radiotherapy for cancer
}

\author{
Lone Gothard $^{\mathrm{a}}$, Joanne Haviland ${ }^{\mathrm{b}}$, Phil Bryson ${ }^{\mathrm{c}}$, Gerard Laden ${ }^{\mathrm{d}}$, Mark Glover ${ }^{\mathrm{e}}$, Steven Harrison ${ }^{\mathrm{f}}$, \\ Mary Woods ${ }^{\mathrm{g}}$, Gary Cook ${ }^{\mathrm{h}}$, Clare Peckitt ${ }^{\mathrm{b}}$, Ann Pearson ${ }^{\mathrm{a}}$, Navita Somaiah ${ }^{\mathrm{a}}$, Anthony Stanton ${ }^{\mathrm{i}}$, \\ Peter Mortimer ${ }^{\mathrm{i}}$, John Yarnold ${ }^{\mathrm{a}, *}$
}

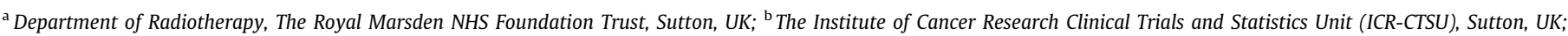

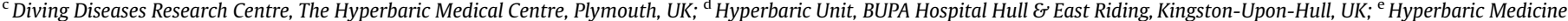

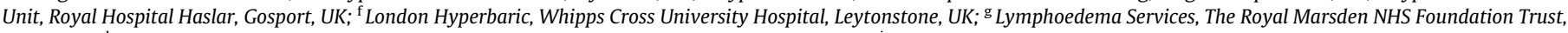

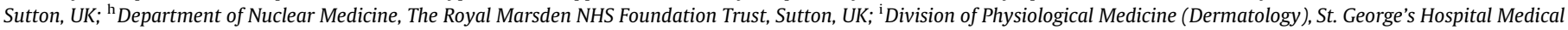
School, London, UK

\section{A R T I C L E I N F O}

\section{Article history:}

Received 13 January 2010

Received in revised form 26 April 2010

Accepted 29 April 2010

Available online 31 May 2010

\section{Keywords:}

Breast cancer

Radiotherapy

Arm lymphoedema

Hyperbaric oxygen therapy

\begin{abstract}
A B S T R A C T
Background: A non-randomised phase II study suggested a therapeutic effect of hyperbaric oxygen (HBO) therapy on arm lymphoedema following adjuvant radiotherapy for early breast cancer, justifying further investigation in a randomised trial.

Methods: Fifty-eight patients with $\geqslant 15 \%$ increase in arm volume after supraclavicular \pm axillary radiotherapy (axillary surgery in $52 / 58$ patients) were randomised in a $2: 1$ ratio to $\mathrm{HBO}(n=38)$ or to best standard care $(n=20)$. The HBO group breathed $100 \%$ oxygen at 2.4 atmospheres absolute for 100 min on 30 occasions over 6 weeks. Primary endpoint was ipsilateral limb volume expressed as a percentage of contralateral limb volume. Secondary endpoints included fractional removal rate of radioisotopic tracer from the arm, extracellular water content, patient self-assessments and UK SF-36 Health Survey Questionnaire.

Findings: Of 53/58 (91.4\%) patients with baseline assessments, 46 had 12-month assessments (86.8\%). Median volume of ipsilateral limb (relative to contralateral) at baseline was $133.5 \%$ (IQR 126.0$152.3 \%$ ) in the control group, and 135.5\% (IQR 126.5-146.0\%) in the treatment group. Twelve months after baseline the median (IQR) volume of the ipsilateral limb was $131.2 \%$ (IQR 122.7-151.5\%) in the control group and 133.5\% (IQR 122.3-144.9\%) in the treatment group. Results for the secondary endpoints were similar between randomised groups.

Interpretation: No evidence has been found of a beneficial effect of HBO in the treatment of arm lymphoedema following primary surgery and adjuvant radiotherapy for early breast cancer.
\end{abstract}

(c) 2010 Elsevier Ireland Ltd. All rights reserved. Radiotherapy and Oncology 97 (2010) 101-107
Reports of hyperbaric oxygen (HBO) therapy in patients at risk of mandibular necrosis following curative radiotherapy for cancer suggest that the evolution of late onset radiation adverse effects can be modified $[1,2]$. Treatment benefit has also been reported in patients with haemorrhagic cystitis and proctitis following pelvic radiation [3-20]. The pathological correlates of the response to hyperbaric oxygen in irradiated tissues have been studied in animals, and include neovascularisation with organisation and reduction in fibrous tissue [21]. Prospective randomised trials of HBO are rare, and include a study reporting benefits in radiation proctitis

\footnotetext{
* Corresponding author. Address: Academic Radiotherapy Unit, The Royal Marsden Hospital, Downs Road, Sutton, Surrey SM2 5PT, UK.

E-mail address: john.yarnold@icr.ac.uk (J. Yarnold).
}

[22]. No serious adverse effects of HBO have been reported in any of these studies.

In a previous study testing $\mathrm{HBO}$ in patients with radiation-induced brachial plexopathy, we detected no evidence of effect [23]. However, $2 / 6$ cases with co-existing chronic arm lymphoedema reported major and persistent improvements in arm volume for at least 12 months after treatment with HBO. This observation was not anticipated, and formed the basis for a non-randomised phase II study in which $3 / 19$ evaluable patients experienced $>20 \%$ reduction in arm volume at 12 months follow-up [24]. Six of 13 evaluable patients also experienced a $>25 \%$ improvement in ${ }^{99} \mathrm{Tc}$-nanocolloid clearance rate from the ipsilateral forearm at 12 months. Overall, there was a statistically significant reduction in ipsilateral arm volume at 12 months follow-up compared with baseline ( $p=0.005$ ). It was this set of data that justified the current randomised phase II trial. 


\section{Patients and methods}

\section{Eligibility and pre-treatment baseline assessments}

Inclusion criteria included ipsilateral arm lymphoedema following treatment for cancer causing $\geqslant 15 \%$ increase in arm volume, freedom from cancer recurrence, physical and psychological fitness for HBO, availability for follow-up and written informed consent. Pre-treatment assessment included advice on standard care for lymphoedema, measurement of arm volume using a perometer, patient self-assessments using a specific quality of life scale in upper limb lymphoedema and the UK SF-36 Health Survey Questionnaire [25]. Patients randomised to the treatment group had magnetic resonance imaging (MRI) of the supraclavicular fossa, axilla and brachial plexus to exclude cancer recurrence; in the event of recurrence, they were withdrawn from the study. There was a 3month run-in period between eligibility and baseline assessments to ensure that all participants were receiving best standard care for their lymphoedema according to the Lymphoedema Framework Best Practice for the Management of Lymphoedema International Consensus (2006) [26]. Baseline assessments included measurement of lymph drainage in the forearm using lymphoscintigraphy and of extracellular water content using a di-electric constant meter in addition to perometer measurements and patient selfassessments.

The trial was approved by Trent Multi-centre Research Ethics Committee and Local Research Ethics Committees at all participating centres. It was registered as an International Standard Randomised Controlled Trial, No. ISRCTN00743308.

\section{Measurement of arm volume, quantitative lymphoscintigraphy and di-} electric constant meter measurements

Arm volumes were measured in an operator-independent manner using a Perometer 400T limb volumeter (Pero-System, Wuppertal, Germany) [27,28]. The perometer consisted of a horizontally mounted measuring frame inside which the dependent arm was positioned. The frame was moved up and down and volume in $\mathrm{ml}$ was automatically calculated from pairs of circumference measurements at $5 \mathrm{~mm}$ intervals from wrist to axilla, obtained opto-electronically. The volume of the ipsilateral limb was expressed as a percentage of the contralateral (control) limb volume. Response was defined in the protocol as $\geqslant 8 \%$ absolute reduction in ipsilateral arm volume on the grounds that this was considered a clinically worthwhile improvement unlikely to be due to supportive measures or changes in lifestyle.

Lymphoscintigraphy was performed on as many volunteers as possible at baseline and at 12 months follow-up. Patients were acclimatised to their surroundings for at least $45 \mathrm{~min}$ before starting. Patients lay supine with both arms resting on the gamma camera detector fitted with low energy, high resolution collimators (Skylight, Philips Medical Systems, Cleveland, USA). A site on the ventral surface of the ipsilateral forearm particularly affected by swelling was selected for injection (typically one-third of the distance from the antecubital crease to the wrist). The site was marked and the distance to the outstretched fingertip and to the olecranon process was measured in $\mathrm{cm}$ to enable relocation to the same position for the repeat scan at 12 months. The corresponding site on the contralateral arm was also marked. ${ }^{99 \mathrm{~m}} \mathrm{Tc}-$ Nanocoll $(0.2 \mathrm{ml})$ in saline, containing approximately $20 \mathrm{MBq}$, was injected subcutaneously in each forearm using a 1-ml syringe and a 23-gauge needle. The site was not massaged. The arms were positioned in supination on the camera face and a 60-s static acquisition was performed. Acquisitions were repeated at 30, 60, 90, 120 and $180 \mathrm{~min}$. Between acquisitions, the patient sat in a waiting room. No exercise was performed. The number of counts recorded within a circular region of interest (area $80 \mathrm{~cm}^{2}$ ), encompassing the depot, was obtained from the computer (Xeleris, GE). The removal rate constant for the radiotracer, $k$ (local lymph flow per unit volume of distribution of tracer, units: $\% \mathrm{~min}^{-1}$ ), was determined from the regression slope of the plot of $\log _{n}$ fraction of counts remaining at the depot against time [29]. No formal definition of response was agreed prior to the study.

Extracellular water content was measured on all volunteers at baseline and 12 months later using di-electric constant measurements [30,31]. The di-electric constant is a dimensionless physical quantity and is directly proportional to the water content in the measured tissue. Patients were acclimatised to their surroundings in a prone position for at least $15 \mathrm{~min}$ before measurements were taken. The patient lay on a bed, with both arms resting along the body with palms facing up. Two sites were selected for measurement; one-third of the distance from the antecubital crease to the wrist (forearm) and one-half of the distance from the antecubital crease to the axilla (upper arm). The sites were marked, and the distance between the wrist/axilla and the antecubital crease was measured in $\mathrm{cm}$ to enable relocation to the same positions for repeat measurements at 12 months. Corresponding sites on the contralateral arm were also marked. Measurements were taken using a Delfin MoistureMeter-D (Delfin Technologies Ltd., www.delfintech.com), an electronic control unit connected to a probe, which recorded the di-electric constant of the skin and subcutaneous tissue. The MoistureMeter-D uses a low power $300 \mathrm{MHz}$ frequency, and the measuring depth was adjusted by changing the size of the probe (the M25 probe aimed to measure extracellular water in the epidermis/dermis and the L50 probe aimed to measure to $5 \mathrm{~mm}$ depth). Three measurements were taken with each probe at each site, and the mean of the three repeat readings at each site was calculated. No formal definition of response was agreed prior to the study.

\section{Quality of life}

Patient self-assessments included a quality of life scale (as yet unpublished) in upper limb lymphoedema developed and validated by a lymphoedema practitioner and the UK SF-36 Health Survey Questionnaire [25]. The lymphoedema quality of life scale consisted of 12 questions designed to assess restrictions to everyday activities such as work, hobbies, bathing, sleep, shopping and choice of clothing, together with pain and self awareness in a similar format to the SF-36 questionnaire. The UK SF-36 Health Survey Questionnaire is a generic, multi-purpose, short-form health survey with 36 questions, yielding an 8-scale profile of functional health and well-being scores as well as psychometrically based physical and mental health summary measures and a preferencebased health utility index. Volunteers were asked to complete the questionnaires before randomisation, at baseline assessments 3 months later ( 1 week prior to start of HBO for volunteers in the treatment group), and 3, 6, 9 and 12 months after the baseline assessments.

\section{Hyperbaric oxygen therapy or control}

Research volunteers were randomised with a ratio of 2:1 (treatment:control) after confirmation of eligibility and consent procedure by a telephone call to the randomisation service of The Institute of Cancer Research Clinical Trials \& Statistics Unit. At the eligibility assessment 3 months prior to baseline assessments, all volunteers were given advice on best standard care, and hosiery was provided/adjusted if appropriate. Volunteers in the treatment group were compressed to 2.4 atmospheres absolute (ATA) (243 kPa) in a hyperbaric chamber at one of the five participating hyperbaric medicine units. Patients breathed $100 \%$ oxygen at pres- 
sure. The total time at 2.4 ATA was 100 min, including two 5-min air breaks. Each participant received a total of 30 pressure exposures, treating 5 days a week for 6 weeks. Volunteers in the control group continued best standard care for lymphoedema.

\section{Endpoints, sample size and analysis}

The primary endpoint was defined as an absolute change of $\geqslant 8 \%$ in the relative volume of the ipsilateral arm vs. contralateral arm at 12 months. Planned secondary endpoints included (i) lymphoscintigraphy, (ii) di-electric constant measurements and (iii) patient self-assessments of arm swelling and physical functioning.

In our HBO pilot study of 19 evaluable patients with arm lymphoedema, the mean reduction in arm volume 12 months posttherapy was $7.68 \%$ with standard deviation of 10.4 [24]. Using this information, a sample size of 63 patients ( 42 treatment: 21 control) was deemed sufficient to provide a clear test of efficacy compared with best standard management. Sixty-three patients provided $90 \%$ power to detect an $8 \%$ absolute difference (standardised difference of 0.8 ) between groups in the reduction of volume in the affected arm (relative to the normal arm) at 12 months after start of therapy compared with baseline (1-sided 5\% significance level). Note that an $8 \%$ absolute reduction in pre-treatment ipsilateral arm volume of $116 \%$ relative to contralateral arm volume represented a $50 \%$ reduction in arm swelling.

Nonparametric methods were used to summarise and analyse the primary and secondary endpoints since distributions of the data were skewed and no suitable transformation could be found. Distributions were summarised using the median and interquartile range (IQR). The Wilcoxon signed rank test was used to investigate within-patient change from baseline to 12 months separately for each treatment group. Change over time was then compared between control and HBO using the Mann-Whitney test. As well as analysing the primary endpoint using the continuous data, perometer measurements of arm volume were also categorised into responder vs. non-responder. Relative risk of response according to treatment group was calculated with 95\% confidence intervals (CI) and tested using the Fisher's exact test.

Subscale scores for the SF-36 questionnaire were calculated using the standard methods described in the scoring manual. The upper limb lymphoedema-specific module of the quality of life questionnaire was analysed by adding together the numerical responses to each of the individual questions to obtain a total score which was transformed to a 0-100 scale - the same method used for the subscales of the SF-36 questionnaire. Subscale scores were summarised using the median and IQR for the control and HBO groups at each time-point.

There was marked scatter of points for some patients' lymphoscintigraphy plots that made the fitting of slopes difficult. In some cases activity appeared to increase after injection, a phenomenon noted previously [32] but for which no explanation is available. Two analyses of the lymphoscintigraphy data were undertaken: (i) all acquisition points for each patient were included and slopes fitted to each plot accordingly; (ii) plots failing to show clearance were excluded altogether and in other plots with outlying points the latter were excluded before fitting the regression slope. Both sets of results are presented.

\section{Results}

\section{Patient demographics, compliance and treatment toxicities}

Eligible patients interested to participate proved difficult to identify despite widespread publicity. Fifty-eight eligible research volunteers with a minimum $15 \%$ increase in arm volume in the years after supraclavicular \pm axillary radiotherapy (axillary surgery
Table 1

Baseline patient characteristics.

\begin{tabular}{lll}
\hline & Control; $N=20(\%)$ & HBO; $N=38(\%)$ \\
\hline Age: mean (SD) & $62.1(9.8)$ & $63.2(10.2)$ \\
Primary surgery & & \\
$\quad$ None & $1(5.0)$ & $2(5.3)$ \\
$\quad$ Wide local excision & $10(50.0)$ & $18(47.4)$ \\
$\quad$ Mastectomy & $9(45.0)$ & $18(47.4)$ \\
Axillary surgery & $18(90.0)$ & $34(89.5)$ \\
$\quad$ Of those with axillary surgery: & $7 / 18(38.9)$ & $3 / 34(8.8)$ \\
$\quad$ Level I/II clearance & $5 / 18(27.8)$ & $12 / 34(35.3)$ \\
$\quad$ Level III clearance & $1 / 18(5.5)$ & $6 / 34(17.6)$ \\
$\quad$ Sampling & $5 / 18(27.8)$ & $13 / 34(38.2)$ \\
$\quad$ Level not known & & \\
Lymphatic RT & $5(25.0)$ & $20(52.6)$ \\
$\quad$ SCF only & $4(20.0)$ & $6(15.8)$ \\
$\quad$ Axilla only & $11(55.0)$ & $12(31.6)$ \\
$\quad$ SCF + axilla & $11.8(9.7)$ & $11.4(8.6)$ \\
Time from RT to & & $109.5(24.2)$ \\
$\quad$ randomisation (yrs): mean (SD) & $\mathrm{n} / \mathrm{a}$ & \\
$\quad$ Time from randomisation & & \\
$\quad$ (eligibility assessment) & & \\
$\quad$ to start of HBO (days): mean (SD) & & \\
\hline
\end{tabular}

in 52/58 cases) were identified and randomised to continue treatment according to best standard management for lymphoedema (control group, $n=20$ ) or to be treated with HBO (treatment group, $n=38$ ). 56/58 were breast cancer patients (55 females, 1 male), and 2/58 had received radiotherapy for Hodgkin's Lymphoma ( $1 \mathrm{fe}-$ male, 1 male). The baseline characteristics for the two randomised groups were very similar, except for a higher rate of axillary sampling rather than clearance in the HBO group (although numbers very small), see Table 1 .

Of the 58 patients randomised, baseline assessments were done in 53 (91.4\%): 17 control and $36 \mathrm{HBO}$. Of the 53 patients with baseline assessments, 46 had 12-month assessments (86.8\%): 16 control and $30 \mathrm{HBO}$. Reasons why patients did not have assessments at baseline and 12 months are shown in Fig. 1.

$5 / 38$ patients reported toxicities due to HBO therapy but completed 30 sessions of treatment. 2/5 developed ear barotraumas on first dive and were offered bilateral myringotomies; $3 / 5$ reported some degree of myopia towards the end of treatment.

\section{Perometer measurements, lymphoscintigraphy and di-electric constant meter measurements}

Results of arm volume measurements at baseline and at 12 months follow-up are shown in Table 2. Forty-six of 58 volunteers were assessed at 12 months, 16 in the control group and 30 in the treatment group. The median volume of the ipsilateral limb expressed as a percentage of contralateral limb volume at baseline was $133.5 \%$ (IQR 126.0-152.3\%) in the control group and $135.5 \%$ (IQR 126.5-146.0\%) in the treatment group. 12 months after baseline the median (IQR) volume of the ipsilateral limb expressed as a percentage of contralateral limb volume was 131.2\% (IQR 122.7$151.5 \%$ ) in the control group and $133.5 \%$ (IQR $122.3-144.9 \%$ ) in the treatment group. The absolute median change from baseline to 12 months was $-0.3 \%$ (IQR $-7.5 \%$ to $5.5 \%, p=0.64$ ) in the control group and $-2.9 \%$ (IQR $-9.4 \%$ to $5.6 \%, p=0.50$ ) in the treatment group. This small decrease in relative arm volume in both treatment groups was not statistically significant, and there were no statistically significant differences between randomised treatment groups in terms of change over time.

In the trial protocol, "response" was defined as $\geqslant 8 \%$ reduction in ipsilateral arm volume relative to contralateral arm volume at 12 months. According to this definition, 30\% (9/30) of patients in 


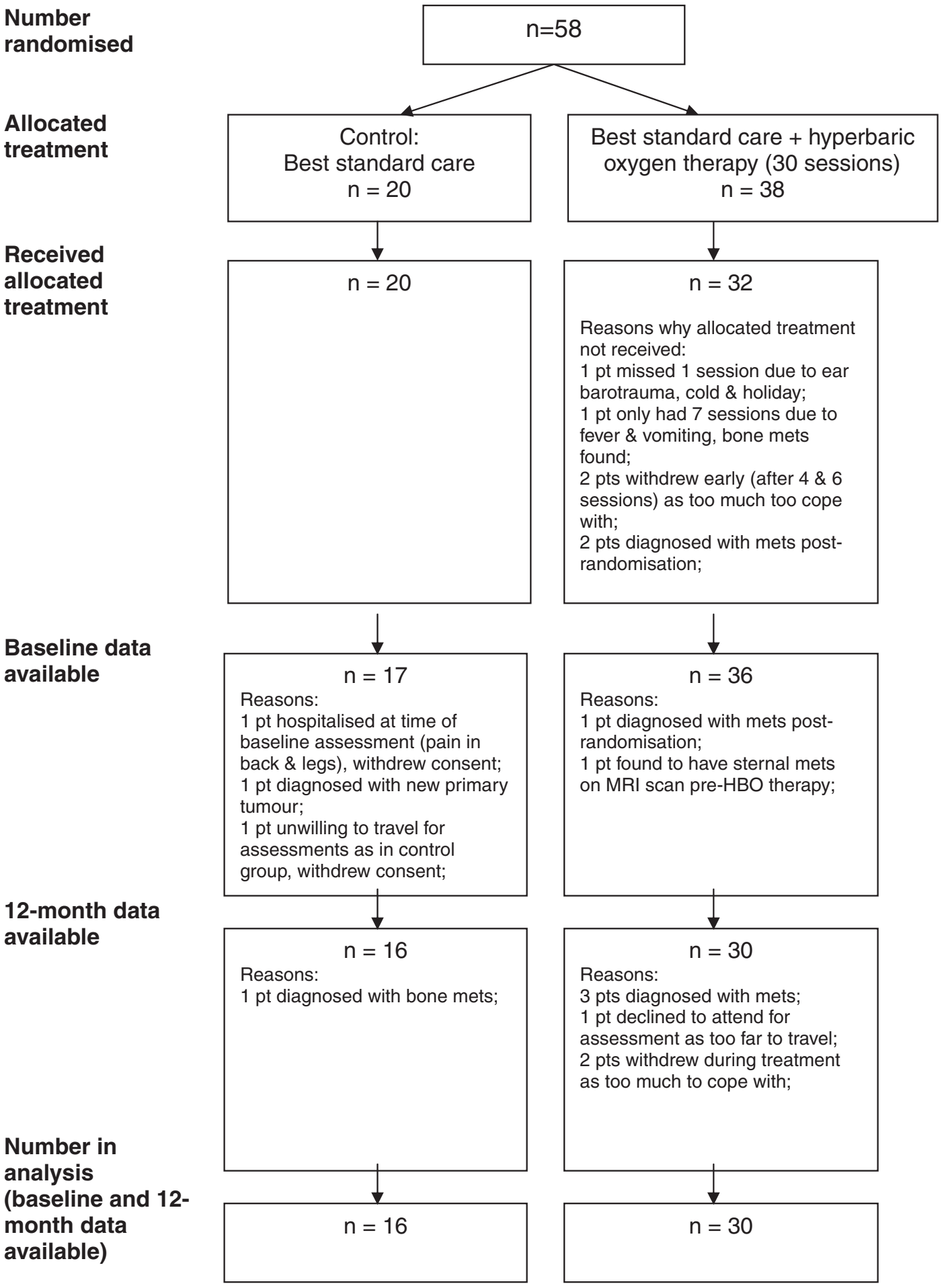

Fig. 1. Trial profile for HOT trial.

the HBO group were classified as responders, compared with $18.8 \%$ $(3 / 16)$ in the control group, corresponding to a relative risk of being a responder for HBO compared with control of 1.60 (95\%CI $0.50-$ 5.09). This was not statistically significant ( $p$-value for Fisher's exact test, $p=0.50$ ).

In both analyses (using complete and edited data), lymphatic clearance rates were similar between the treatment groups at baseline and at 12 months. The analysis of within-patient change from baseline to 12 months showed that there was no clear improvement for either treatment group (Table 3a and b).
The analysis of change over time for the di-electric constant measurements suggested a possible greater improvement (i.e. reduction in fluid volume) for $\mathrm{HBO}$ patients compared with control, for the upper arm results (Table 4).

Specific quality of life scale in upper limb lymphoedema together with the UK SF-36 Health Survey Questionnaire

Table 5 and Fig. 2 show that patient ratings from the lymphoedema-specific questionnaire were generally lower across the fol- 
Table 2

Perometer measurements of arm volume at baseline and 12 months according to treatment group.

\begin{tabular}{|c|c|c|}
\hline $\begin{array}{l}\text { Perometer measurements of arm } \\
\text { volume: median (interquartile range) }\end{array}$ & $\begin{array}{l}\text { Control } \\
N=16(\%) \\
\mathrm{ml}\end{array}$ & $\begin{array}{l}\mathrm{HBO} \\
N=30(\%) \\
\mathrm{ml}\end{array}$ \\
\hline \multicolumn{3}{|l|}{ Baseline } \\
\hline Ipsilateral arm volume & $\begin{array}{l}3350 \\
(2659 \text { to } 4037)\end{array}$ & $\begin{array}{l}3189 \\
(2735 \text { to } 3971)\end{array}$ \\
\hline Contralateral arm volume & $\begin{array}{l}2550 \\
\text { (1921 to } 2878 \text { ) }\end{array}$ & $\begin{array}{l}2434 \\
\text { (1983 to } 2821 \text { ) }\end{array}$ \\
\hline $\begin{array}{l}\text { Ipsilateral/contralateral } \\
\text { arm volume (\%) }\end{array}$ & $\begin{array}{l}133.5 \\
(126.0 \text { to } 152.3)\end{array}$ & $\begin{array}{l}135.5 \\
(126.5 \text { to } 146.0)\end{array}$ \\
\hline \multicolumn{3}{|l|}{12 months } \\
\hline Ipsilateral arm volume & $\begin{array}{l}3350 \\
(2581 \text { to } 3897)\end{array}$ & $\begin{array}{l}3061 \\
(2673 \text { to } 4066)\end{array}$ \\
\hline Contralateral arm volume & $\begin{array}{l}2435 \\
\text { (2072 to 2841) }\end{array}$ & $\begin{array}{l}2326 \\
\text { (2046 to 2661) }\end{array}$ \\
\hline $\begin{array}{l}\text { Ipsilateral/contralateral } \\
\text { arm volume }(\%)\end{array}$ & $\begin{array}{l}131.2 \\
(122.7 \text { to } 151.5)\end{array}$ & $\begin{array}{l}133.5 \\
(122.3 \text { to } 144.9)\end{array}$ \\
\hline \multicolumn{3}{|l|}{ Change from baseline to 12 months ${ }^{\mathrm{a}, \mathrm{b}}$} \\
\hline Absolute change ipsilateral arm & $\begin{array}{l}-3.5 \\
(-243.5 \text { to } 76.7) \\
p=0.44\end{array}$ & $\begin{array}{l}-41.0 \\
(-166.0 \text { to } 59.5) \\
p=0.14\end{array}$ \\
\hline Absolute change contralateral arm & $\begin{array}{l}1.0 \\
(-129.2 \text { to } 94.0) \\
p=0.94\end{array}$ & $\begin{array}{l}-20.5 \\
(-82.5 \text { to } 65.5) \\
p=0.55\end{array}$ \\
\hline $\begin{array}{l}\text { Absolute change ipsilateral/ } \\
\text { contralateral arm volume (\%) }\end{array}$ & $\begin{array}{l}-0.3 \\
p=0.64\end{array}$ & $\begin{array}{l}-2.9 \\
(-9.4 \text { to } 5.6) \\
p=0.50\end{array}$ \\
\hline
\end{tabular}

Results of Mann-Whitney tests comparing change in parameters over time between control and HBO groups: ipsilateral arm $p=0.83$; contralateral arm $p=0.75 ;$ ipsilateral/contralateral arm $p=0.93$.

a Change from baseline to 12 months expressed as (12 months - baseline); -ve indicates a decrease in arm volume (improvement) and +ve indicates an increase (deterioration).

${ }^{b}$ Wilcoxon signed rank test for comparison of baseline vs. 12 months.

low-up period in the HBO group compared with control, indicating fewer problems. Some patients also wrote comments in their questionnaire booklets indicating satisfaction with the treatment, and observed improvements in arm movement. SF-36 subscale scores for functioning, general health, etc. were very similar between the treatment groups over time (data not shown).

\section{Discussion}

This randomised trial failed to confirm earlier reports of benefit of HBO in women with chronic arm lymphoedema following adju- vant radiotherapy to the lymphatic pathways $[23,24]$. One possible explanation is that patients in our previous studies became better at managing their lymphoedema through contact with other patients and health professionals during the course of the research. In the current trial, there was a 3-month run-in period between the eligibility assessments and treatment which ensured that all participants received best standard care prior to HBO therapy. One argument against this is that, in our previous study, lymphoscintigraphy suggested improved clearance rates of extracellular fluid from the arm 12 months in 6/13 patients after $\mathrm{HBO}$, a change that would not be expected on the basis of better passive control of arm volume [24].

There are several reasons why the present trial may have missed a therapeutic effect. The small sample size increases the risk of chance imbalances in prognostic factors between randomised groups and reduces the size of treatment effect that can be reliably detected. Although the two groups were not perfectly balanced with respect to treatment variables, differences in numbers receiving axillary radiotherapy are not likely to be critical. In most patients, the supraclavicular field includes the level III nodes, and standard tangential fields to the breast or chest wall include the lower axilla (corresponding to level I). Perhaps the long average interval (almost 12 years) between radiotherapy and HBO was just too long to enable remodelling of mature fibrotic tissue, although one of the most dramatic complete responses in our first study was seen in a woman with gross lymphoedema of 20 years duration [23]. The long average interval in the present trial reflected the scarcity of patients currently treated in the UK with axillary radiotherapy, a practice that may now be returning in the context of positive axillary sentinel node biopsy [33]. On an individual patient basis, it is not possible to assess the relative contributions of axillary surgery and lymphatic radiotherapy to arm lymphoedema. If axillary surgery was the dominant causative factor for lymphoedema, the trial may have missed a therapeutic effect of HBO on the radiotherapy-induced element. This would mean that the patient population could not offer proof of principle that HBO had an effect against radiation-induced arm lymphoedema. Although the pathogenesis of lymphoedema caused by surgery and radiotherapy is not well understood, there are likely to be similarities that render uncertainty over the relative contributions of the two causative agents largely irrelevant.

The only secondary endpoint raising the possibility of therapeutic effect was a comparison of response rate in the randomised groups. Thirty percent $(9 / 30)$ of patients in the HBO group were classified as responders, compared with $18.8 \%(3 / 16)$ in the control

Table 3

Lymphoscintigraphy data at baseline and 12 months according to treatment group.

\begin{tabular}{|c|c|c|c|c|}
\hline \multirow{2}{*}{$\begin{array}{l}\text { Lymphatic clearance rate }\left(\% \min ^{-1}\right) \text { : } \\
\text { median (interquartile range) }\end{array}$} & \multicolumn{2}{|c|}{ All observed data included in analysis } & \multicolumn{2}{|c|}{ Unreliable data excluded from analysis } \\
\hline & $\begin{array}{l}\text { Control } \\
N=12(\%)\end{array}$ & $\begin{array}{l}\mathrm{HBO} \\
N=28(\%)\end{array}$ & $\begin{array}{l}\text { Control } \\
N=12(\%)\end{array}$ & $\begin{array}{l}\mathrm{HBO} \\
N=28(\%)\end{array}$ \\
\hline \multicolumn{5}{|l|}{ Baseline } \\
\hline Ipsilateral forearm & $\begin{array}{l}-0.013 \\
(-0.035 \text { to } 0.006)\end{array}$ & $\begin{array}{l}-0.040 \\
(-0.056 \text { to }-0.014)\end{array}$ & $\begin{array}{l}-0.052 \\
(-0.125 \text { to }-0.031)\end{array}$ & $\begin{array}{l}-0.058 \\
(-0.096 \text { to }-0.048)\end{array}$ \\
\hline Contralateral forearm & $\begin{array}{l}-0.056 \\
(-0.079 \text { to }-0.011)\end{array}$ & $\begin{array}{l}-0.064 \\
(-0.079 \text { to }-0.027)\end{array}$ & $\begin{array}{l}-0.066 \\
(-0.125 \text { to }-0.054)\end{array}$ & $\begin{array}{l}-0.081 \\
(-0.140 \text { to }-0.057)\end{array}$ \\
\hline \multicolumn{5}{|l|}{12 months } \\
\hline Ipsilateral forearm & $\begin{array}{l}-0.023 \\
(-0.073 \text { to } 0.005)\end{array}$ & $\begin{array}{l}-0.050 \\
(-0.069 \text { to }-0.020)\end{array}$ & $\begin{array}{l}-0.104 \\
(-0.139 \text { to }-0.056)\end{array}$ & $\begin{array}{l}-0.074 \\
(-0.113 \text { to }-0.051)\end{array}$ \\
\hline Contralateral forearm & $\begin{array}{l}-0.059 \\
(-0.072 \text { to }-0.007)\end{array}$ & $\begin{array}{l}-0.051 \\
(-0.087 \text { to }-0.017)\end{array}$ & $\begin{array}{l}-0.066 \\
(-0.077 \text { to }-0.061)\end{array}$ & $\begin{array}{l}-0.087 \\
(-0.113 \text { to }-0.053)\end{array}$ \\
\hline \multicolumn{5}{|l|}{ Change from baseline to 12 months $\mathrm{s}^{\mathrm{a}}$} \\
\hline Absolute change ipsilateral forearm & $\begin{array}{l}-0.009 \\
(-0.074 \text { to } 0.023)\end{array}$ & $\begin{array}{l}-0.015 \\
(-0.035 \text { to } 0.007)\end{array}$ & $\begin{array}{l}-0.062 \\
(-0.103 \text { to } 0.085)\end{array}$ & $\begin{array}{l}-0.013 \\
(-0.024 \text { to } 0.018)\end{array}$ \\
\hline Absolute change contralateral forearm & $\begin{array}{l}0.007 \\
(-0.032 \text { to } 0.075)\end{array}$ & $\begin{array}{l}0.006 \\
(-0.023 \text { to } 0.040)\end{array}$ & $\begin{array}{l}0.007 \\
(-0.021 \text { to } 0.201)\end{array}$ & $\begin{array}{l}0.003 \\
(-0.045 \text { to } 0.046)\end{array}$ \\
\hline
\end{tabular}

a Change from baseline to 12 months expressed as (12 months - baseline); -ve indicates an improvement in clearance rate and +ve a deterioration. 
Table 4

Dielectric constant measurements of extracellular water content at baseline and 12 months according to treatment group.

\begin{tabular}{|c|c|c|c|}
\hline $\begin{array}{l}\text { Di-electric measurements of arm fluid volume change } \\
\text { from baseline to } 12 \text { months } s^{\text {a }} \text { median (interquartile range) }\end{array}$ & Probe used & $\begin{array}{l}\text { Control } \\
N=13^{\mathrm{b}}(\%)\end{array}$ & $\begin{array}{l}\mathrm{HBO} \\
N=30(\%)\end{array}$ \\
\hline Ipsilateral upper arm & Skin & $-0.7(-2.5$ to 4$)$ & $-2.0(-4.2$ to 1.7$)$ \\
\hline Contralateral upper arm & Skin & $0(-1.2$ to 1.3$)$ & $0(-1.4$ to 0.7$)$ \\
\hline Ipsilateral forearm & Skin & 0.7 ( -3 to 2.7$)$ & $1.8(-3.2$ to 4.3$)$ \\
\hline Contralateral forearm & Skin & $1(-1$ to 2.2$)$ & $1.3(-0.7$ to 2.4$)$ \\
\hline Ipsilateral upper arm & Subcutaneous & $0.3(-0.7$ to 2.5$)$ & $-1.3(-3.5$ to 1.2$)$ \\
\hline Contralateral upper arm & Subcutaneous & $0(-0.3$ to 1$)$ & $-0.3(-1.4$ to 0$)$ \\
\hline Ipsilateral forearm & Subcutaneous & $-0.3(-4.2$ to 3.2$)$ & $0.3(-3.1$ to 4.7$)$ \\
\hline Contralateral forearm & Subcutaneous & $0.3(-1.0$ to 0.8$)$ & $1.0(-0.7$ to 2.1$)$ \\
\hline
\end{tabular}

a Change from baseline to 12 months expressed as (12 months - baseline); -ve indicates decrease in arm fluid volume (improvement) and +ve an increase (deterioration).

b Three missing.

Table 5

Patient self-assessments of effects of lymphoedema from baseline to 12 months according to treatment group.

\begin{tabular}{lll}
\hline $\begin{array}{l}\text { Total standardised score from } \\
\text { lymphoedema questionnaire } \\
\text { (range 0-100); median (IQR) }\end{array}$ & Control & HBO \\
\hline Baseline & 47.9 & 50.0 \\
$N=17$ control and 35 HBO & $(18.7-64.6)$ & $(27.1-64.6)$ \\
3 months & 58.3 & 33.3 \\
$N=17$ control and 33 HBO & $(20.8-66.7)$ & $(20.8-59.4)$ \\
6 months & 47.9 & 32.3 \\
$N=16$ control and 32 HBO & $(18.7-64.1)$ & $(17.7-53.6)$ \\
9 months & 33.3 & 43.7 \\
$N=16$ control and 32 HBO & $(15.1-64.6)$ & $(19.3-58.3)$ \\
12 months & 45.8 & 37.5 \\
$N=16$ control and 31 HBO & $(13.0-62.5)$ & $(20.8-52.1)$ \\
\hline
\end{tabular}

${ }^{a}$ Higher scores reflect worse effects of lymphoedema on activities, etc.

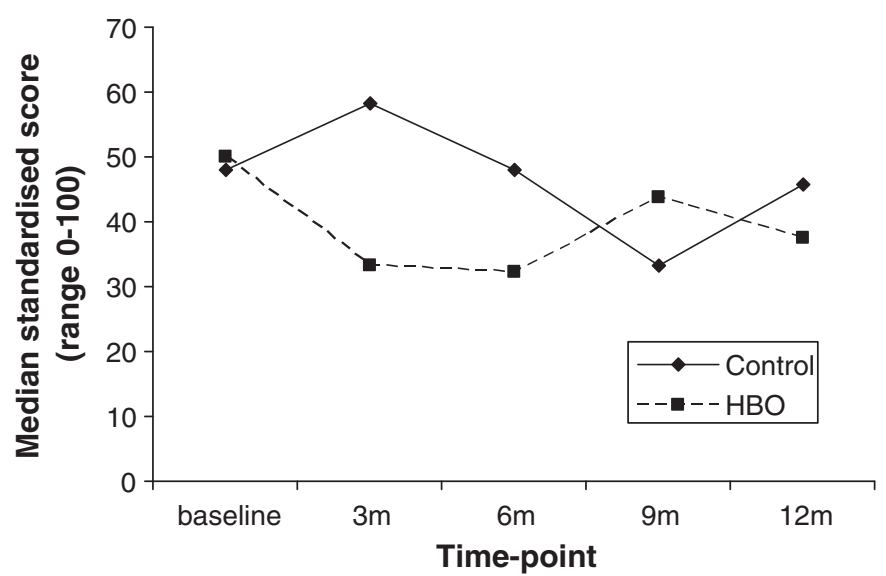

Fig. 2. Patient self-assessments of effects of lymphoedema according to time-point and treatment group.

group, a difference that was not statistically significant. Neither of the functional measures of lymphatic clearance, including rate of clearance of extracellular water measured by lymphoscintigraphy and size of extracellular compartment measured using di-electric constant, suggested that a therapeutic effect of HBO was missed by the volume measurements. The reproducibility of the former measurements was not high, placing limits on the sensitivity of this technique to small differences in clearance rate. The patient self-assessments of functional outcome and quality of life were also consistent with the external measures of HBO effect in reporting no differences between randomised groups. In conclusion, this randomised trial has not confirmed earlier reports of a therapeutic effect of $\mathrm{HBO}$ on arm lymphoedema following primary surgery and radiotherapy for early breast cancer.

\section{Conflict of interest statement}

We declare no conflict of interest.

\section{Acknowledgements}

The authors are grateful for the enormous support and commitment shown by the volunteers participating in this study and for the contributions offered by their consumer representatives, Mrs. Joyce Pritchard and Mrs. Pamela Jukes. The authors acknowledge the contribution of the Trial Steering Committee (Dr. Jane Dobbs, Dr. John Ross, Mrs. Anita Wallace), the Data Monitoring and Ethics Committee (Prof. Stan Dische, Prof. Mike Peters and Prof. Richard Gray), staff at the Lymphoedema and Nuclear Medicine Departments at the Royal Marsden Hospital in Sutton and Castle Hill Hospital in Hull as well as nursing and technical staff at the Hyperbaric Medicine Units in Gosport, Hull, London, Newport and Plymouth. The authors acknowledge Cancer Research, UK and the Department of Health that jointly funded the work. Statistical input was undertaken at the ICR Clinical Trials and Statistics Unit with funding from Cancer Research, UK.

\section{References}

[1] Marx RE, Johnson RP, Kline SN. Prevention of osteoradionecrosis: a randomized prospective clinical trial of hyperbaric oxygen versus penicillin. J Am Dent Assoc 1985; 111:49-54.

[2] Marx RE. Hyperbaric medicine practice: chapter 23, radiation injury to tissue hyperbaric medicine practice. 2nd ed. Best Publishing Company; 1994. p. 448501.

[3] Bevers RF, Bakker DJ, Kurth KH. Hyperbaric oxygen treatment for haemorrhagic radiation cystitis. Lancet 1995;346:803-5.

[4] Lee HC, Liu CS, Chiao C, Lin SN. Hyperbaric oxygen therapy in hemorrhagic radiation cystitis: a report of 20 cases. Undersea Hyperb Med 1994;21:321-7.

[5] Schoenrock GJ, Cianci P. Treatment of radiation cystitis with hyperbaric oxygen. Urology 1986;27:271-2.

[6] Nakada T, Yamaguchi T, Sasagawa I, Kubota Y, Suzuki H, Izumiya K. Successful hyperbaric oxygenation for radiation cystitis due to excessive irradiation to uterus cancer. Eur Urol 1992;22:294-7.

[7] Kindwall EP. Hyperbaric medicine practice: chapter 1 a history of hyperbaric medicine. In: Kindwall EP, Whelan HT, editors. Hyperbaric medicine practice. Best Publishing Company; 1994. p. 2-15.

[8] Weiss JP, Mattei DM, Neville EC, Hanno PM. Primary treatment of radiationinduced hemorrhagic cystitis with hyperbaric oxygen: 10-year experience. J Urol 1994;151:1514-7.

[9] Norkool DM, Hampson NB, Gibbons RP, Weissman RM. Hyperbaric oxygen therapy for radiation-induced hemorrhagic cystitis. J Urol 1993;150:332-4.

[10] Bem J, Bem S, Singh A. Use of hyperbaric oxygen chamber in the management of radiation-related complications of the anorectal region: report of two cases and review of the literature. Dis Colon Rectum 2000;43:1435-8.

[11] Hamour AA, Denning DW. Hyperbaric oxygen therapy in a woman who declined colostomy. Lancet 1996;348:197. 
[12] Neurath MF, Branbrink A, Meyer zum Buschenfelde KH, Lohse AW. A new treatment for severe malabsorption due to radiation enteritis. Lancet 1996;347:1302.

[13] Kitta T, Shinohara N, Shirato H, Otsuka H, Koyanagi T. The treatment of chronic radiation proctitis with hyperbaric oxygen in patients with prostate cancer. BJU Int 2000;85:372-4.

[14] Moulin C, Li V, Loizzo F, Faudemay C, Hostein J. Value of hyperbaric oxygen in the hemostatic treatment of chronic radiation-induced recto-sigmoiditis. Gastroenterol Clin Biol 1993;17:520-1.

[15] Nakada T, Kubota Y, Sasagawa I, et al. Therapeutic experience of hyperbaric oxygenation in radiation colitis. Report of a case. Dis Colon Rectum 1993;36:962-5.

[16] Dall'Era MA, Hampson NB, Hsi RA, Madsen B, Corman JM. Hyperbaric oxygen therapy for radiation induced protopathy in men treated for prostate cancer. $J$ Urol 2006;176:87-90.

[17] Gouello JP, Bouachour G, Person B, Ronceray J, Cellier P, Alquier P. The role of hyperbaric oxygen therapy in radiation-induced digestive disorders. 36 cases. Presse Med 1999;28:1053-7.

[18] Aanderud L, Thorsen E, Brattebo G, Forland M, Kristensen G. Hyperbaric oxygen treatment for radiation reactions. Tidsskr Nor Laegeforen 2000;120: 1020-2.

[19] Woo TC, Joseph D, Oxer H. Hyperbaric oxygen treatment for radiation proctitis. Int J Radiat Oncol Biol Phys 1997;38:619-22.

[20] Warren DC, Feehan P, Slade JB, Cianci PE. Chronic radiation proctitis treated with hyperbaric oxygen. Undersea Hyperb Med 1997;24:181-4.

[21] Marx RE, Ehler WJ, Tayapongsak P, Pierce LW. Relationship of oxygen dose to angiogenesis induction in irradiated tissue. Am J Surg 1990;160:519-24.

[22] Clarke RE, Tenorio LM, Hussey JR, et al. Hyperbaric oxygen treatment of chronic refractory radiation proctitis: a randomized and controlled doubleblind crossover trial with long-term follow-up. Int J Radiat Oncol Biol Phys 2008;72:134-43.
[23] Pritchard J, Anand P, Broome J, et al. Double-blind randomized phase II study of hyperbaric oxygen in patients with radiation-induced brachial plexopathy. Radiother Oncol 2001;58:279-86.

[24] Gothard L, Stanton A, MacLaren J, et al. Non-randomised phase II trial of hyperbaric oxygen therapy in patients with chronic arm lymphoedema and tissue fibrosis after radiotherapy for early breast cancer. Radiother Oncol 2004;70:217-24

[25] Ruta D, Garratt A, Abdalla M, Buckingham K, Russell I. The SF 36 health survey questionnaire. A valid measure of health status. BMJ 1993;307:448-9.

[26] Lymphoedema framework. Best practice for the management of lymphoedema. International consensus. London: MEP Ltd.; 2006.

[27] Goltner E, Fischbach JU, Monter B, Kraus A, Vorherr H. Objective measurement of lymphedema after mastectomy. Dtsch Med Wochenschr 1985;110:949-52.

[28] Stanton AW, Northfield JW, Holroyd B, Mortimer PS, Levick JR. Validation of an optoelectronic limb volumeter (perometer). Lymphology 1997;30:77-97.

[29] Modi S, Stanton AW, Mortimer PS, Levick JR. Clinical assessment of human lymph flow using removal rate constants of interstitial macromolecules: a critical review of lymphoscintigraphy. Lymphat Res Biol 2007;5:183-202.

[30] Thomas BJ, Ward LC, Cornish BH. Bioimpedance spectrometry in the determination of body water compartments: accuracy and clinical significance. Appl Radiat Isot 1998;49:447-55.

[31] Ward LC, Czerniec S, Kilbreath SL. Quantitative bioimpedance spectroscopy for the assessment of lymphoedema. Breast Cancer Res Treat 2008

[32] Modi S, Stanton AW, Mellor RH, Peters AM, Levick JR, Mortimer PS. Regional distribution of epifascial swelling and epifascial lymph drainage rate constants in breast cancer-related lymphedema. Lymphat Res Biol 2005;3:3-15.

[33] Rutgers EJ, Meijnen P, Bonnefoi H. Clinical trials update of the European Organization for Research and Treatment of Cancer Breast Cancer Group. Breast Cancer Res 2004;6:165-9. 